\title{
A systematic review of the indications for genetic testing and prophylactic gastrectomy among patients with hereditary diffuse gastric cancer
}

\author{
Rajini Seevaratnam $\cdot$ Natalie Coburn . \\ Roberta Cardoso • Matthew Dixon • \\ Alina Bocicariu $\cdot$ Lucy Helyer
}

Received: 13 May 2011 / Accepted: 31 October 2011/Published online: 10 December 2011

(C) The International Gastric Cancer Association and The Japanese Gastric Cancer Association 2011

\begin{abstract}
Background Hereditary diffuse gastric cancer (HDGC) is a familial cancer syndrome specifically associated with germline mutations to the E-cadherin (CDH1) gene. HDGC is characterized by autosomal dominance and high penetrance and a high cumulative risk for advanced gastric cancer. Our purpose in this study was to identify and synthesize findings from all articles on: (1) current recommendations for CDH1 screening and prophylactic gastrectomy; (2) CDH1 testing results in HDGC patients; and (3) prophylactic gastrectomy results in HDGC patients.

Methods Systematic electronic literature searches were conducted using Medline, Embase, and the Cochrane Central Register of Controlled Trials from 1985 to 2009.

Results Seventy articles were included in this review. Among patients with a positive family history of gastric
\end{abstract}

Electronic supplementary material The online version of this article (doi:10.1007/s10120-011-0116-3) contains supplementary material, which is available to authorized users.

R. Seevaratnam · N. Coburn $(\bowtie) \cdot$ R. Cardoso $\cdot$ M. Dixon .

A. Bocicariu

Sunnybrook Research Institute, Sunnybrook Health Sciences

Centre, Toronto, Canada

e-mail: natalie.coburn@sunnybrook.ca

N. Coburn

Division of Surgical Oncology, Sunnybrook Health Sciences Centre and Odette Cancer Centre, Suite T2-60, 2075 Bayview Ave, M4N 3M5 Toronto, ON, Canada

\section{Dixon}

Department of Surgery, Maimonides Medical Center, Brooklyn, USA

L. Helyer

Division of General Surgery, Department of Surgery,

Dalhousie University, Halifax, Canada cancer, 1085 were screened from 454 families, and 38.4\% tested positive. Mutation-positive families also had a considerable family history of breast and colon cancer. Of the 322 patients screened for $\mathrm{CDH} 1$ mutations by current HDGC screening criteria, 29.2\% tested positive. Among the $76.8 \%$ of patients who underwent prophylactic gastrectomy following positive $\mathrm{CDH} 1$ test results, $87.0 \%$ had positive final histopathology results and $64.6 \%$ had signet ring cells identified. Some of the patients with negative final histopathology results had opted to undergo prophylactic gastrectomy prior to $\mathrm{CDH} 1$ testing, and were ultimately found to be negative for $\mathrm{CDH} 1$ mutations.

Conclusion CDH1 mutation testing in families with a history of gastric cancer and prophylactic gastrectomy in mutation-positive patients are recommended for the management of HDGC.

Keywords Hereditary diffuse gastric cancer - CDH1 screening · Prophylactic gastrectomy - Genetic testing · Clinical management

\section{Introduction}

Gastric cancer (GC) is one of the most common forms of cancer and causes of cancer death worldwide [1]. The majority of cases are sporadic in nature; however, familial clustering is observed in about $10 \%$ of the cases [2]. Of those with familial aggregation, $1-3 \%$ are diagnosed with hereditary diffuse gastric cancer (HDGC) [2]. According to the International Gastric Cancer Linkage Consortium (IGCLC), the following criteria must be met for a diagnosis of HDGC: (1) two or more documented cases of diffuse gastric cancer (DGC) in first- or second-degree relatives, with at least one diagnosed before the age of 50 , or (2) 
three or more cases of documented DGC in first- or seconddegree relatives, independent of age of onset [3, 4]. Families with an aggregation of GC and an index case with DGC but not fulfilling the IGCLC criteria for HDGC are categorized as having familial diffuse gastric cancer (FDGC), whereas familial clustering of GC in which the histopathology of the tumor is unknown is designated as familial gastric cancer (FGC) [2, 3, 5]. A family history of intestinal carcinoma can also be present and families with this type of aggregation are classified as having familial intestinal gastric cancer (FIGC) $[2,3,5]$. In this review we will focus only on HDGC.

HDGC is an autosomal dominant cancer syndrome caused by germline mutations to the CDH1 gene that encodes for the cell-to-cell adhesion protein E-cadherin [68]. Genetic linkage between CDH1 mutations and HDGC was first described by Guilford et al. [9, 10], who identified germline truncating E-cadherin mutations in three New Zealand Maori families in 1998. Currently about 100 inactivating germline mutations in the $\mathrm{CDH} 1$ gene have been published, with the most common types being small insertions or deletions (35\%) and missense mutations (28\%) [6]. Other mutation types (nonsense, splice site, and large exonic deletions) have also been identified [6]. Regardless of mutation type, the majority $(75 \%)$ result in a truncated loss-of-function protein [11]. CDH1 mutations are found among all ethnicities, with large clusters being identified in New Zealand and Canada [11-13]. A paradox is noted for Asian countries, where a high incidence of sporadic GC is present, but a low incidence of CDH1 mutations has been found. The reason for this is unknown $[2,5,7]$.

The penetrance of CDH1 germline mutations in HDGC is relatively high. The estimated lifetime cumulative risk of developing $\mathrm{GC}$ is $67 \%$ in men and $83 \%$ in women, with a mean age at diagnosis of 38-40 years (range: $14-85$ years) [14]. The presence of a CDH1 mutation has also been linked to an increased risk of lobular breast cancer among women, with one study estimating a cumulative lifetime risk of 39\% [14]. However, another recent publication by the IGCLC suggests that the risk of gastric cancer is over $80 \%$ for both men and women, and the risk of lobular breast cancer is $60 \%$ for women [4]. This high rate of penetrance highlights the importance of identifying CDH1 mutation carriers. More importantly, an early diagnosis of HDGC may translate to improved prognosis and longer survival rates for these patients. Therefore, the purpose of this review is to identify and synthesize findings from all articles on: (1) current recommendations for $\mathrm{CDH} 1$ screening and prophylactic gastrectomy; (2) $\mathrm{CDH} 1$ testing results in patients with a family history of $\mathrm{GC}$, as well as those with HDGC; and (3) prophylactic gastrectomy results in HDGC patients.

\section{Methods}

Data sources

Electronic literature searches were conducted using Medline and Embase from 1 January 1985 to 31 December 2009 according to the search algorithm presented in Appendix A. Search terms included: [exp Stomach Cancer/or (((gastric or stomach) adj1 cancer\$) or ((gastric or stomach) adj1 carcinoma) or ((gastric or stomach) adj1 adenocarcinoma) or ((gastric or stomach) adj1 neoplasm\$)).mp.] and [exp Gastrectomy/or (surgery or surgical).mp. or (prophylaxis or prophylactic or prevent\$).mp.] and [Familial Cancer/ or familial.mp. or "family history".mp. or hereditary.mp. or cadherin\$.mp. or CDH1.mp. or HDGC.mp.]. A separate search of the Cochrane Central Register of Controlled Trials (1985-2009) was performed using the search term "gastric cancer". No attempt was made to locate unpublished material.

Study selection and review process

To be eligible, studies had to meet the following criteria: (1) provide new or modified recommendations for $\mathrm{CDH} 1$ screening and/or prophylactic gastrectomy in HDGC patients; (2) report CDH1 testing results in HDGC patients or families; (3) provide prophylactic gastrectomy results in HDGC patients or families; (4) include patients with a diagnosis of HDGC or a family history of HDGC; and (5) be published in peer-reviewed journals in English. Studies were excluded according to the following criteria: (1) involved animals and/ or ex vivo samples; (2) included patients without HDGC; and (3) did not provide new data. No study design restriction was used. All electronic search titles, selected abstracts, and fulltext articles were independently reviewed by a minimum of two reviewers (NC, LH, RS, AB). Disagreements on study inclusion/exclusion were resolved with a consensus meeting.

\section{Data extraction}

A systematic approach to data extraction was used to produce a descriptive summary of participants, interventions, and study findings. The first reviewer (RS) independently extracted the data and a second reviewer (RC) checked the data extraction. No attempt was made to contact authors for additional information.

\section{Results}

Literature search

A total of 561 titles/abstracts were identified from the electronic searches and reference lists for preliminary 
review. After removal of duplicates and screening for relevant titles and abstracts, a total of 96 articles were submitted for a full-text review. A total of 70 articles [3, 5-8, 10-74] met our inclusion criteria and were included in this review (Fig. 1).

Recommendations for $\mathrm{CDH} 1$ screening and prophylactic gastrectomy

In 1999, the IGCLC published the first set of recommendations for $\mathrm{CDH} 1$ testing [3], which called for mutation screening for all patients diagnosed with HDGC according to two criteria (Table 1). Shortly after, members of the British Columbia Cancer Agencyand the Stanford Cancer Center, as well as individual members of the IGCLC published broader sets of clinical criteria to be used as indications for CDH1 mutation testing [5, 7, 8, 11, 15-18] (Table 1). These revised guidelines called for mutation testing of patients with family histories of only one diagnosed case of DGC, lobular breast cancer, colon cancer, or signet ring cell colon cancer. Isolated individuals with a diagnosis of DGC either prior to age 35 or 45 , as well as individuals with a diagnosis of both DGC and lobular breast cancer without any family history, were also included as criteria for CDH1 mutation testing. In 2006, Blair et al. [11] published the recommendations by The New Zealand HDGC Group for the diagnosis and management of HDGC in New Zealand, providing recommendations for both screening and prophylactic gastrectomy by age. It recommended patients under 14 years not be tested for CDH1 mutations, while those over 16 years should be. Prophylactic gastrectomy was not recommended for patients aged less than 16 years; however, delaying

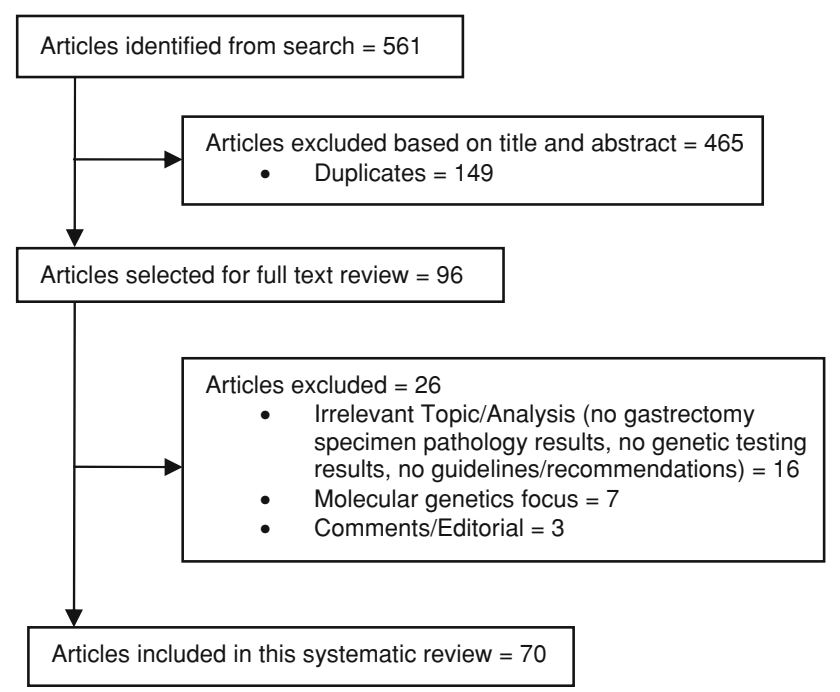

Fig. 1 Article selection flow prophylactic gastrectomy beyond age 30 years was thought to carry a significant risk for cancer development.

\section{CDH1 mutation screening results}

A total of 46 articles $[6,10,13-15,17,19-58]$ reporting $\mathrm{CDH} 1$ mutation testing results were included in this review. Among patients with a positive family history of GC, 1085 patients from 454 families were screened. Positive family history in these patients was defined as: (1) considerable family history of GC (histology unknown) and documented DGC, (2) breast cancer (histology unknown), (3) documented lobular breast cancer, and (4) colon cancer. However, there was only one documented case for a family history of signet ring cell colon cancer (Table 2, for full details see Appendix B). Of those screened, $38.4 \%$ were CDH1 mutation-positive (Table 2, Appendix B). The age of family members diagnosed with cancer ranged considerably, from 14 to 90 years for GC (histology unknown), 29 to 67 years for DGC, 30 to 90 years for breast cancer, 49 to 66 years for lobular breast cancer, and 30 to 82 years for colon cancer (Table 2, Appendix B). The distribution of cancer among men and women was nearly equivalent for GC when the histology was unknown (47 and 53\%, respectively); whereas a higher percentage of women (59\%) had documented DGC compared to men (41\%) (Appendix B). Among 86 additional family members screened after a relative tested positive, $62.8 \%$ tested positive (data not shown).

A total of 9 articles [13, 15, 17, 24, 42, 45, 46, 51, 56] reported CDH1 testing results according to HDGC screening criteria (Table 3). Among those with HDGC, 322 were screened using both the IGCLC and modified IGCLC CDH1 screening criteria, and $29 \%$ tested positive (Table 3). However, among families with two or more cases of GC with at least one case of DGC and a diagnosis prior to 50 years, of the 148 patients screened, $47 \%$ tested positive. In a similar fashion, among families with three or more cases of GC irrespective of age of onset with at least one case of DGC, of the 59 screened patients only $10 \%$ tested positive. When both of these criteria, IGCLC and modified CDH1, were considered, 35\% tested positive out of 229 patients screened. Considering only those isolated individuals diagnosed with DGC prior to 45 years, of the 19 patients who were screened, $10.5 \%$ tested positive; whereas a diagnosis of DGC prior to 35 years gave an $8 \%$ positive test rate among 37 individuals screened. The modified CDH1 screening criteria of one family member diagnosed with DGC and another with lobular breast cancer did not result in any positive mutation tests; however, when families with multiple cases of lobular breast cancer with or without cases of DGC were considered, $23 \%$ tested positive (three of 13 patients screened). One of two 
Table 1 Current recommendations for $\mathrm{CDH} 1$ screening and prophylactic gastrectomy

\begin{tabular}{|c|c|}
\hline Reference & Recommendations \\
\hline aldas [3] & $\begin{array}{l}\text { IGCLC criteria } \\
\text { 1. Two or more documented cases of DGC in first or second degree relatives, with at least one diagnosed before the age } \\
\text { 50; or } \\
\text { 2. Three or more cases of documented DGC in first or second degree relatives, independently of age of onset } \\
\text { Modified criteria }\end{array}$ \\
\hline $\begin{array}{l}\text { Brooks-Wilson } \\
\text { [15] }\end{array}$ & $\begin{array}{l}\text { 1. Two or more documented cases of DGC in first degree relatives, with at least one diagnosed before age } 50 \\
\text { 2. Two or more cases of GC, with at least one DGC diagnosed before age } 50 \\
\text { 3. Three or more documented cases of DGC in first degree relatives, diagnosed at any age } \\
\text { 4. Three or more cases of GC, diagnosed at any age, with at least one documented case of DGC } \\
\text { 5. Isolated individual diagnosed with DGC before age } 45 \\
\text { 6. One family member diagnosed with DGC and another with LBC (no other criteria met); or } \\
\text { 7. One family member diagnosed with DGC and another with CC (no other criteria met) }\end{array}$ \\
\hline Cisco $[8,16]$ & $\begin{array}{l}\text { 1. Families with } 2 \text { or more cases of DGC, with at least one case diagnosed before the age of } 50 \text { years } \\
\text { 2. Families with } 3 \text { or more cases of DGC, diagnosed at any age } \\
\text { 3. Isolated individuals diagnosed with DGC before the age of } 35 \text { years } \\
\text { 4. Isolated individuals with both DGC and LBC } \\
\text { 5. Families with one member with DGC and another with either LBC or SRCC; or } \\
\text { 6. Families with multiple cases of LBC, with or without a case of DGC (i.e., in families with LBC alone) } \\
\text { Genetic testing may be appropriate for isolated patients with pathological features strongly suggestive of HDGC } \\
\text { 1. Bland signet ring cells } \\
\text { 2. Signet ring cells present in small clusters or as single cells } \\
\text { 3. Apparent containment within the superficial gastric mucosa; or } \\
\text { 4. Absence of intestinal-type adenocarcinoma or intestinal metaplasia }\end{array}$ \\
\hline Lynch [17] & $\begin{array}{l}\text { 1. Family with } 2 \text { or more cases of GC with at least } 1 \text { case of DGC diagnosed before the age of } 50 \\
\text { 2. Family with multiple cases of LBC with or without DGC in first or second degree relatives } \\
\text { 3. Isolated individual diagnosed with DGC at less than } 35 \text { years from a low-incidence population } \\
\text { 4. Personal history of DGC and LBC-no family history } \\
\text { 5. Family with } 3 \text { or more cases of GC diagnosed at any age, one or more of which is a documented case of DGC, no other } \\
\text { criteria met; or } \\
\text { 6. Family with one or more cases of both DGC and SRCC }\end{array}$ \\
\hline Blair [11] & $\begin{array}{l}\text { Management of HDGC-presymptomatic CDH1 mutation testing recommendations by age } \\
<14 \text { years: children should not be tested } \\
\text { 14-16 years: consider on a case-by-case basis } \\
>16 \text { years: all family members should be offered testing } \\
\text { Management of HDGC-prophylactic gastrectomy recommendations by age } \\
<16 \text { years: risk of advanced GC is very low; prophylactic gastrectomy not recommended before growth completed } \\
\text { 16-20 years: carcinoma risk }<1 \% \text {; surveillance gastroscopy is a more appropriate approach } \\
20-30 \text { years: carcinoma risk } 4 \% \text { by } 30 \text { years; prophylactic gastrectomy is recommended. Delaying prophylactic } \\
\text { gastrectomy beyond this age carries significant risk }\end{array}$ \\
\hline
\end{tabular}

IGCLC International Gastric Cancer Linkage Consortium, $H D G C$ hereditary diffuse gastric cancer, $D G C$ diffuse gastric cancer, $G C$ gastric cancer, $L B C$ lobular breast cancer, $C C$ colon cancer, SRCC signet ring cell colon cancer

individuals tested positive when meeting the criteria of one family member diagnosed with DGC and another with colon cancer. When the specific presence of signet ring cell colon cancer was required along with a case of DGC, 33\% (one of three patients) tested positive.
Prophylactic gastrectomy results

Twenty-eight articles [12, 13, 17, 19, 23, 24, 26, 34, 37, 44, 51, 52, 59-74] reported prophylactic gastrectomy results in HDGC patients (Fig. 2, for full details see Appendix C). A 


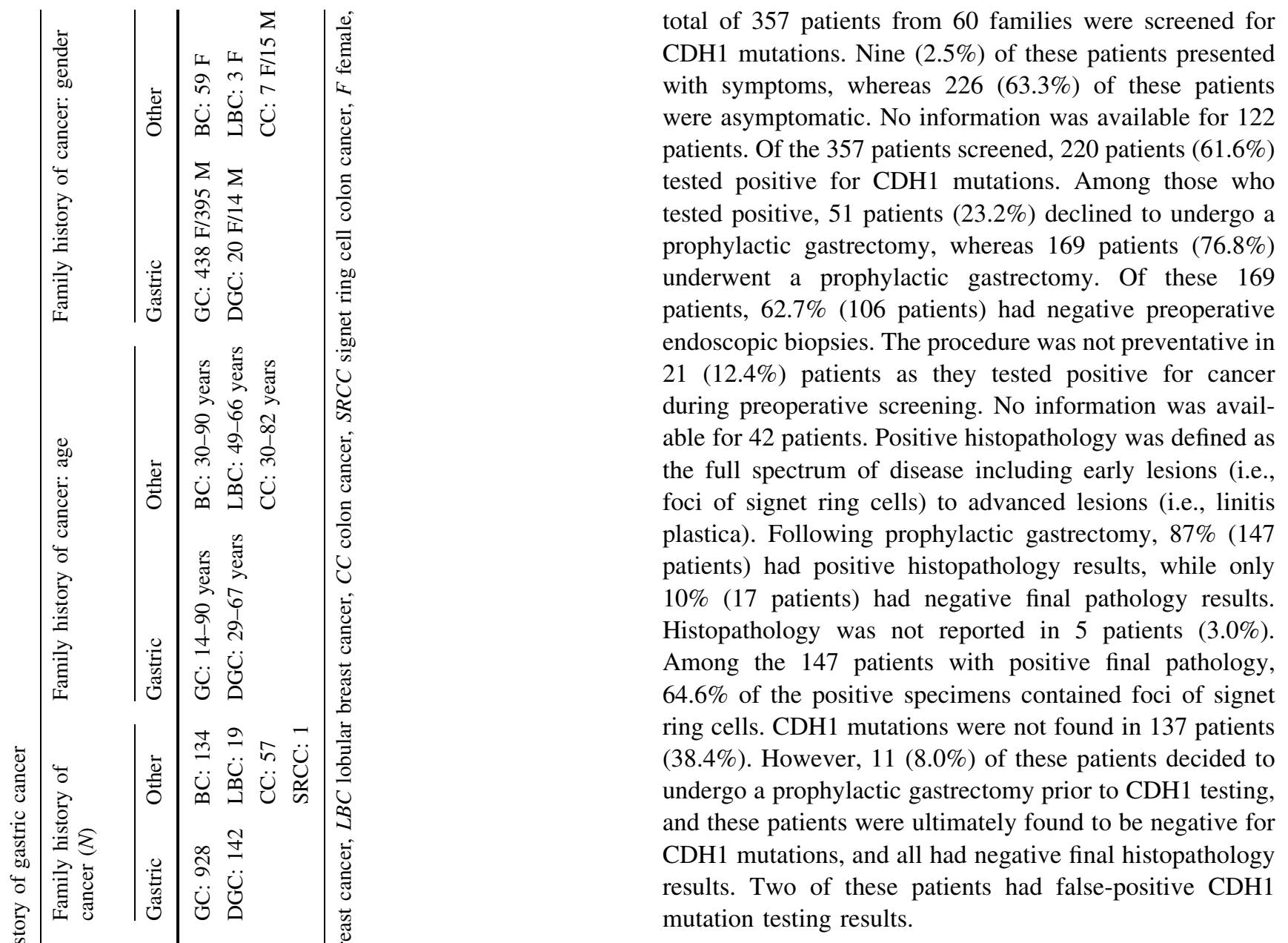

\section{Discussion}

Accurate diagnosis and classification of HDGC is important for the improved prognosis of patients with DGC and their families. Due to the high penetrance of $\mathrm{CDH} 1$ mutations, we performed a systematic review of the literature to identify the current recommendations for $\mathrm{CDH} 1$ mutation screening, the rate of positive test results, and the rates according to current $\mathrm{CDH} 1$ mutation testing recommendations. We also identified the rate of positive pathology results among patients with a CDH1 mutation undergoing prophylactic gastrectomy for HDGC. Previous reviews have been published; however, this analysis differs from others by including a wider range of reports (such as case reports), as well as by focusing on the clinical perspective as opposed to the molecular genetics.

The first set of guidelines for the management of HDGC was published by the IGCLC in 1999 [3]. Due to the highly lethal nature of DGC, the IGCLC advocated for CDH1 mutation testing, pre- and post-test genetic counseling, and a multi-disciplinary team for patient support [3]. At this time, $25 \%$ of families were predicted to carry an 
Table $3 \mathrm{CDH} 1$ testing results according to HDGC screening criteria

\begin{tabular}{|c|c|c|c|}
\hline Reference & HDGC Criteria & $\begin{array}{l}N \text { screened by } \\
\text { HDGC criteria }\end{array}$ & $\begin{array}{l}\text { Positive CDH1 tests by } \\
\text { HDGC criteria }\end{array}$ \\
\hline \multirow{7}{*}{$\begin{array}{l}\text { Brooks- } \\
\text { Wilson } \\
{[15]}\end{array}$} & $\begin{array}{l}2 \text { or more documented cases of DGC in first degree relatives, with at least } 1 \\
\text { diagnosed before age } 50\end{array}$ & 15 & $8(53.3 \%)$ \\
\hline & 2 or more cases of GC, with at least 1 DGC diagnosed before age 50 & 10 & $4(40 \%)$ \\
\hline & 3 or more documented cases of DGC in first degree relatives, diagnosed at any age & 1 & 0 \\
\hline & $\begin{array}{l}3 \text { or more cases of GC, diagnosed at any age, with at least } 1 \text { documented case of } \\
\text { DGC }\end{array}$ & 3 & 0 \\
\hline & Isolated individual diagnosed with DGC at $<45$ years & 9 & 0 \\
\hline & 1 family member diagnosed with DGC and another with LBC (no other criteria met) & 3 & 0 \\
\hline & 1 family member diagnosed with DGC and another with $\mathrm{CC}$ (no other criteria met) & 1 & $1(100 \%)$ \\
\hline $\begin{array}{l}\text { Gayther } \\
\text { [24] }\end{array}$ & An index case of DGC with at least 2 other first degree relatives with confirmed GC & 10 & $3(30 \%)$ \\
\hline \multirow{4}{*}{$\begin{array}{c}\text { Kaurah } \\
{[13]}\end{array}$} & Single case of DGC diagnosed in a person aged $<35$ years & 6 & 0 \\
\hline & At least $2 \mathrm{GC}$ cases with 1 case diagnosed as DGC in person younger than 50 years & 26 & $14(53.8 \%)$ \\
\hline & At least $3 \mathrm{GC}$ cases at any age, 1 of which was confirmed DGC & 5 & 0 \\
\hline & 2 confirmed DGC, both diagnosed in people older than 50 years & 1 & $1(100 \%)$ \\
\hline \multirow{5}{*}{$\begin{array}{r}\text { Lynch } \\
{[17]^{\mathrm{a}}}\end{array}$} & Family with 2 or more cases of GC, with at least 1 DGC diagnosed before age 50 & 83 & $38(46 \%)$ \\
\hline & $\begin{array}{l}\text { Family with } 3 \text { or more cases of GC diagnosed at any age, } 1 \text { or more of which is a } \\
\text { documented case of DGC (no other criteria met) }\end{array}$ & 30 & $1(3 \%)$ \\
\hline & $\begin{array}{l}\text { Family with multiple cases of LBC with or without DGC in first or second degree } \\
\text { relatives }\end{array}$ & 13 & $3(23 \%)$ \\
\hline & $\begin{array}{l}\text { Isolated individual diagnosed with DGC at }<35 \text { years, from a low-incidence } \\
\text { population }\end{array}$ & 31 & $3(10 \%)$ \\
\hline & Family with 1 or more cases of both DGC and SRCC & 3 & $1(33 \%)$ \\
\hline $\begin{array}{l}\text { Richards } \\
\text { [42] }\end{array}$ & $\begin{array}{l}\text { Two or more cases of GC in first degree relatives with one affected before age 50; or } \\
3 \text { or more cases of GC regardless of age }\end{array}$ & 8 & $3(37.5 \%)$ \\
\hline \multirow[t]{2}{*}{$\begin{array}{l}\text { Roviello } \\
\text { [45] }\end{array}$} & $\begin{array}{l}2 \text { or more documented cases of DGC in first or second degree relatives, with at least } \\
1 \text { diagnosed before age } 50\end{array}$ & 8 & 0 \\
\hline & $\begin{array}{l}3 \text { or more documented cases of DGC in first or second degree relatives regardless of } \\
\text { age }\end{array}$ & 6 & $1(16.7 \%)$ \\
\hline $\begin{array}{l}\text { Roviello } \\
\text { [46] }\end{array}$ & $\begin{array}{l}\text { Two or more documented cases of DGC in first or second degree relatives with at } \\
\text { least one affected before age } 50 \text {; or } 3 \text { or more documented cases of DGC in first or } \\
\text { second degree relatives regardless of age }\end{array}$ & 14 & $2(14.3 \%)$ \\
\hline \multirow{7}{*}{$\begin{array}{l}\text { Suriano } \\
{[51]}\end{array}$} & 2 or more documented cases of DGC diagnosed before age 50 & 6 & $2(33 \%)$ \\
\hline & 2 or more cases of GC, with at least one DGC before age 50 & 8 & $3(37.5 \%)$ \\
\hline & $\begin{array}{l}3 \text { or more cases of GC, diagnosed at any age, with at least } 1 \text { documented case of } \\
\text { DGC }\end{array}$ & 4 & $1(25 \%)$ \\
\hline & Isolated individual diagnosed with DGC at $<45$ years & 10 & $2(20 \%)$ \\
\hline & Isolated individual diagnosed with both DGC and LBC & 1 & $1(100 \%)$ \\
\hline & 1 family member diagnosed with DGC and another with LBC & 1 & 0 \\
\hline & 1 family member diagnosed with DGC and another with $\mathrm{CC}$ & 1 & 0 \\
\hline Yoon $[56]$ & $\begin{array}{l}\text { Presence of at least } 2 \mathrm{GC} \text { patients within first degree relatives and at least one patient } \\
\text { diagnosed before age } 50\end{array}$ & 5 & $2(40 \%)$ \\
\hline Total & & 322 & $94(29 \%)$ \\
\hline
\end{tabular}

$H D G C$ hereditary diffuse gastric cancer, $D G C$ diffuse gastric cancer, $G C$ gastric cancer, $L B C$ lobular breast cancer, $C C$ colon cancer, $S R C C$ signet ring colon cancer

${ }^{a}$ Percentage of expected positive results based on the experience of the BCCA (British Columbia Cancer Agency) HDGC program

inactivating germline CDH1 mutation that fit one of the two criteria for an HDGC diagnosis [3]. Although lobular breast cancer, colorectal cancer, and prostate cancer were documented in mutant gene carriers, the inclusion of these tumors as diagnostic criteria was premature [3]. Additionally, the prevalence of mutations in patients without a family history of GC was unknown; thus, the IGCLC believed it was premature to offer genetic testing for 
Fig. 2 Summary of prophylactic gastrectomy results in hereditary diffuse gastric cancer (HDGC) patients. Eleven patients underwent prophylactic gastrectomy prior to CHD1 testing and they were ultimately found to be negative for $\mathrm{CDH} 1$ mutations and pathological microscopic foci. Two of the patients had false-positive preoperative screening results

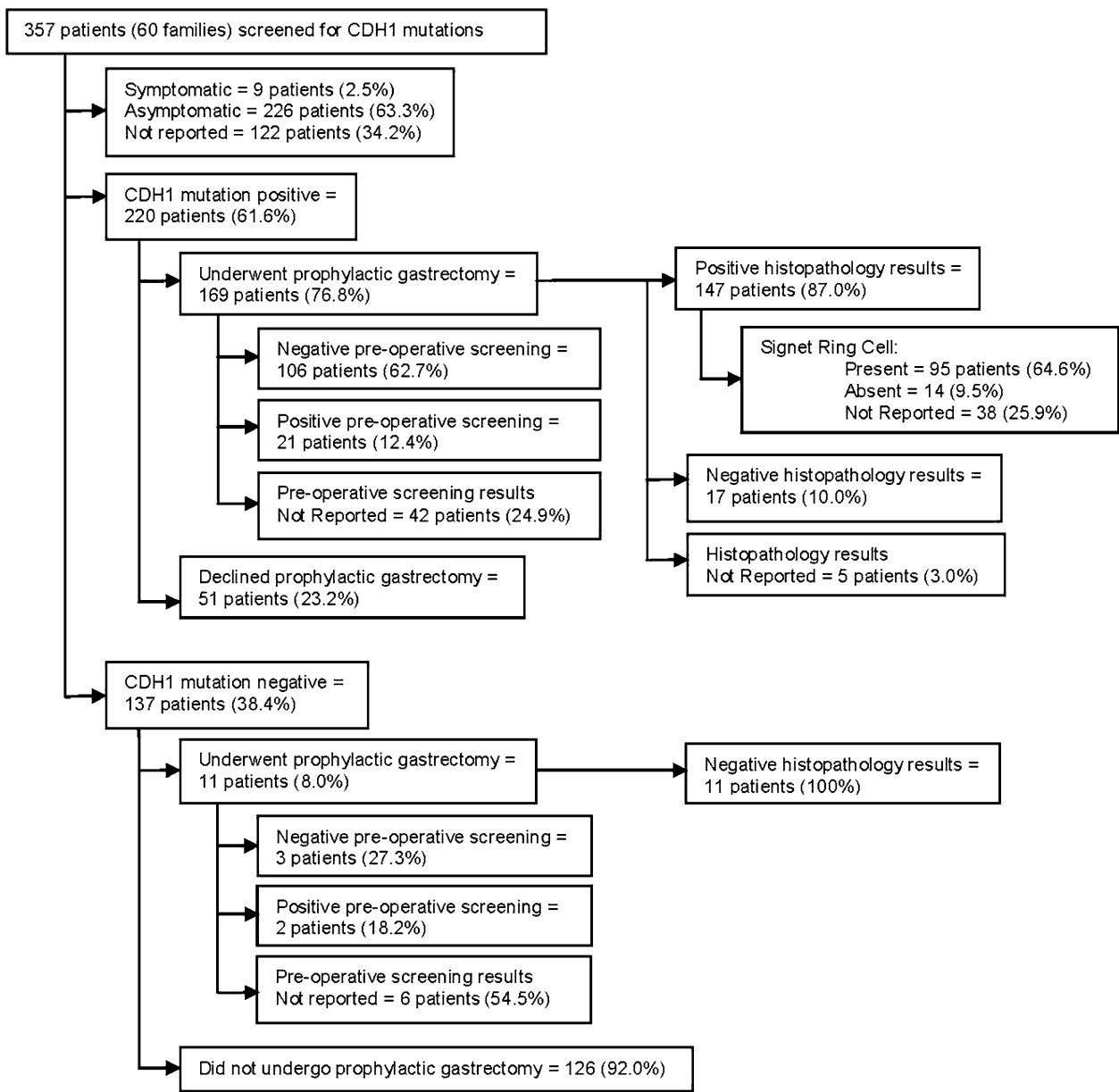

sporadic cases [3]. Since then, the prevalence of CDH1 mutations in families with a history of lobular breast cancer and/or colon cancer, as well as the prevalence of CDH1 mutations among young individuals with GC and no family history of the disease from low-incidence populations, has been documented and the criteria for $\mathrm{CDH} 1$ testing have been modified [5, 7, 8, 11, 15-18] (Table 1). We found that patients with a family history of GC (histology unknown) and documented DGC who tested positive for CDH1 mutations also had a family history of breast cancer and/or colon cancer (Table 2). We also found a higher percentage of women $(59 \%)$ had documented DGC compared to men (41\%) (Appendix B). Patients fulfilling the modified criteria have an estimated $30-50 \%$ likelihood of harboring $\mathrm{CDH} 1$ mutations $[8,16]$. Isolated cases of DGC in young individuals from a low-incidence population have a $20 \%$ probability of harboring a CDH1 mutation [18]. We report similar rates according to $\mathrm{CDH} 1$ screening criteria (Table 3 ). The IGCLC have recently published updated guidelines adopting these new modified criteria for CDH1 screening [4]. They also reported the updated cumulative lifetime risk of DGC development to be greater than $80 \%$ for men and women, as well as an updated cumulative lifetime risk of lobular breast cancer development to $60 \%$ in women [4]. Members of the Stanford Cancer Center have expanded the criteria for referral for genetic testing to include patients with pathological features strongly suggestive of HDGC (Table 1). They suggest that CDH1 testing be performed in these individuals to determine the necessity for a total rather than a subtotal gastrectomy $[8,16]$.

The identification of CDH1 mutations in HDGC families is important to clarify the risk of DGC developing in the future for family members. A negative test result does not mean the patient will not develop GC [3]. These patients should still be followed up with gastric screening similar to that done in at-risk families, as it is possible a mutation exists in the $\mathrm{CDH} 1$ gene that has not yet been discovered [7]. Currently, all patients who have undergone a prophylactic gastrectomy despite a negative test result (or prior to determining the results of CDH1 screening) have been deemed negative for cancer upon histological examination (Fig. 2). On the other hand, a positive test result implies the patient may face a greater than $80 \%$ lifetime chance of developing GC [4]. Mutation screening is not 
recommended for minors under the age of 14 , and a caseby-case analysis is considered for minors aged 14-16 years [11]. If a CDH1 mutation is identified, it is recommended that asymptomatic family members proceed to genetic screening by their early 20 s $[8,16]$. A positive test result is the strongest indicator that a prophylactic gastrectomy should be performed.

Immunoreactive studies of gastric specimens harboring CDH1 mutations show diminished or absent E-cadherin expression. This is consistent with a biallelic inactivation of the CDH1 gene by a 2nd hit mechanism [5]. The most frequent 2 nd hit mechanism in sporadic DGC is promoter hypermethylation [75, 76]. Loss of hererozygosity at the $\mathrm{CDH} 1$ locus or a second CDH1 mutation is less frequent [76]. Given CDH1's high penetration in heterozygotes, the development of DGC is reasonably expected to be even higher in those with biallelic inactivation and can therefore be used as a marker for an even further increase in susceptibility.

Prophylactic gastrectomy for prevention of HDGC

In 1999, the IGCLC advocated a prophylactic gastrectomy in CDH1-positive patients as an effective method of prevention of the development of GC [3]. In the young, healthy population, prophylactic gastrectomy was estimated to be associated with a 1-2\% mortality, $10-20 \%$ major acute morbidity (mainly from the esophagojejunostomy), and $100 \%$ long-term morbidity related to weight loss, rapid intestinal transit, dumping syndrome, diarrhea, and a requirement for lifelong vitamin B supplementation [3]. Other studies suggest mortality risks may be higher, at $2-4 \%[8,16]$. Due to the greater risk assumed by patients undergoing prophylactic gastrectomy, members of the IGCLC recommended that gastrectomy be offered by centers performing at least 25 gastrectomies per year with a surgical mortality of less than 5\% [18]. As such, the IGCLC suggests that patients undergoing prophylactic gastrectomy be assigned a multi-disciplinary team, and this team should work in a high-volume cancer center with perioperative mortality rates of less than $1 \%$ for fit patients undergoing total gastrectomy [4].

The largest single-center experience with prophylactic gastrectomy for CDH1 mutation carriers comes from Newfoundland, Canada [12, 17]. Hebbard et al. [12] reported outcomes from 23 patients who underwent prophylactic total gastrectomy. They reported no mortality, a $17 \%$ major complication rate, $48 \%$ overall complication rate, and a median length of hospital stay of 11 days (range: 7-107 days). Microscopic foci of intramucosal invasive carcinoma were found in $96 \%$ of patients $(22 / 23)$ despite only 9\% (2/23) having positive preoperative endoscopic biopsies [12]. A subset of surgical data (17 of the 23 patients) was published by Lynch et al. [17] and reported an average surgical time of $244 \mathrm{~min}$ (range: 120-580 min), and an estimated blood loss of $1000 \mathrm{~mL}$ (range: $400-3000 \mathrm{~mL}$ ), with 3 patients $(18 \%)$ requiring blood transfusion of 1-2 units of red blood cells, these results being consistent with the proposed morbidity and mortality risks for prophylactic gastrectomy [17].

The optimal timing of prophylactic gastrectomy remains unknown. The New Zealand HDGC group recommends the procedure take place when a patient is in their 20s and before the age of 30 , because delaying prophylactic gastrectomy beyond this age carries a cumulative risk estimate of $4 \%$ for advanced disease by age 30 for both men and women (Table 1). The occurrence of advanced disease at 50 years is $21 \%$ in men and $46 \%$ in women [11]. The Stanford group recommends performing prophylactic gastrectomy 5 years earlier than the age at which the youngest family member developed clinically apparent DGC $[8,16]$, as this appears to permit surgery when cancers are confined to the gastric mucosa without lymph node involvement [8, 16]. Timing can have important implications for young women who have not completed child-bearing. Some experts say that delay of prophylactic gastrectomy in young female $\mathrm{CDH} 1$ mutation carriers is reasonable, considering the metabolic consequences of total gastrectomy during pregnancy [5]. A recent study, however, has demonstrated that a successful term pregnancy following prophylactic gastrectomy is possible [77].

The IGCLC emphasized the importance of performing a prophylactic total gastrectomy and pathologically identifying both the esophageal and duodenal mucosa at the ends of the surgical specimen [3]. This was based on a finding of GC after prophylactic subtotal gastrectomy in one gene carrier [[3], [24]]. Additionally, it is well recognized that prophylactic gastrectomy specimens commonly have multiple foci of malignant cells diffusely distributed throughout the specimen. Therefore, leaving residual stomach further exposes the at-risk patient to the development of GC [24, 26]. Although CDH1 mutation carriers who undergo prophylactic gastrectomy are usually asymptomatic (63.3\% of cases) and have negative preoperative (i.e., endoscopy and radiology imaging) screening results (62.7\% of cases), the final pathology results in $87.0 \%$ of cases displayed positive histology. The majority (64.6\%) of cases displayed foci of signet ring cells and were therefore considered to have early lesions. The remaining cases demonstrated linitis plastica.

Not all specimens from CDH1 mutation carriers will demonstrate positive histology. Approximately $20-30 \%$ of CDH1 mutation carriers will demonstrate incomplete penetrance of the gene, and would therefore never go on to develop clinically significant disease [5]. The possibility of a false-negative pathology result must also be discussed. In 
2005 Gaya et al. [65] reported a case of apparent nonpenetrance of HDGC, as no foci of adenocarcinoma were found in a prophylactic gastrectomy specimen from a patient with a truncating $\mathrm{CDH} 1$ mutation. However, a subsequently published analysis of the histology blocks in this patient, reviewed by a laboratory specializing in HDGC, identified carcinoma [66]. Consequently, it is recommended that histopathology of the total surgical specimen be performed by clinical laboratories specialized in HDGC [4].

\section{Conclusion}

HDGC is a highly lethal autosomal dominant cancer syndrome with high penetrance, and is caused by germline mutations to the $\mathrm{CDH} 1$ gene. We found that $38.4 \%$ of patients with a family history of GC tested positive. Mutation-positive families also had a history of breast and colon cancer. Among 86 additional family members screened after a relative tested positive, $62.8 \%$ tested positive. When patients were screened for CDH1 mutations by current HDGC screening criteria, $29.2 \%$ tested positive. Among CDH1 mutation carriers, $77 \%$ of patients underwent prophylactic gastrectomy and $87 \%$ had positive final histopathology. $\mathrm{CDH} 1$ mutation testing in families with a history of GC, and prophylactic gastrectomy in mutationpositive patients are recommended. All patients undergoing prophylactic gastrectomy prior to $\mathrm{CDH} 1$ testing were found to be CDH1 mutation-negative and had negative final histopathology. Prophylactic gastrectomy in mutationnegative patients is not recommended.

Acknowledgments This research is funded by the Canadian Cancer Society (grant \#019325). Dr. Coburn has received the Career Scientist Award through the Ontario Ministry of Health and Long-Term Care.

\section{References}

1. Mathers CD, Loncar D. Projections of global mortality and burden of disease from 2002 to 2030. PLoS Med. 2006;3(11):e442.

2. Oliveira C, Seruca R, Carneiro F. Genetics, pathology, and clinics of familial gastric cancer. Int J Surg Pathol. 2006;14(1):21-33.

3. Caldas C, Carneiro F, Lynch HT, Yokota J, Wiesner GL, Powell SM, et al. Familial gastric cancer: overview and guidelines for management. J Med Genet. 1999;36(12):873-80.

4. Fitzgerald RC, Hardwick R, Huntsman D, Carneiro F, Guilford P, Blair V, et al. Hereditary diffuse gastric cancer: updated consensus guidelines for clinical management and directions for future research. J Med Genet. 2010;47(7):436-44.

5. Oliveira C, Seruca R, Carneiro F. Hereditary gastric cancer. Best Pract Res. 2009;23(2):147-57.

6. Guilford P, Humar B, Blair V. Hereditary diffuse gastric cancer: translation of $\mathrm{CDH} 1$ germline mutations into clinical practice. Gastric Cancer. 2010;13(1):1-10.
7. Suriano G, Ferreira P, Mateus AR, Correia J, Henriques L, Seruca R. Genetics of hereditary diffuse gastric cancer: progress and future challenges. Future Oncol. 2006;2(3):363-70.

8. Cisco RM, Norton JA. Hereditary diffuse gastric cancer: surgery, surveillance and unanswered questions. Future Oncol. 2008;4(4):553-9.

9. Guilford P, Hopkins J, Harraway J, McLeod M, McLeod N, Harawira $\mathrm{P}$, et al. E-cadherin germline mutations in familial gastric cancer. Nature. 1998;392(6674):402-5.

10. Guilford PJ, Hopkins JB, Grady WM, Markowitz SD, Willis J, Lynch $\mathrm{H}$, et al. E-cadherin germline mutations define an inherited cancer syndrome dominated by diffuse gastric cancer. Hum Mutat. 1999;14(3):249-55.

11. Blair V, Martin I, Shaw D, Winship I, Kerr D, Arnold J, et al. Hereditary diffuse gastric cancer: diagnosis and management. Clin Gastroenterol Hepatol. 2006;4(3):262-75.

12. Hebbard PC, Macmillan A, Huntsman D, Kaurah P, Carneiro F, Wen X, et al. Prophylactic total gastrectomy (PTG) for hereditary diffuse gastric cancer (HDGC): the Newfoundland experience with 23 patients. Ann Surg Oncol. 2009;16(7):1890-5.

13. Kaurah P, MacMillan A, Boyd N, Senz J, De Luca A, Chun N, et al. Founder and recurrent CDH1 mutations in families with hereditary diffuse gastric cancer. JAMA. 2007;297(21):2360-72.

14. Pharoah PD, Guilford P, Caldas C. Incidence of gastric cancer and breast cancer in $\mathrm{CDH} 1$ (E-cadherin) mutation carriers from hereditary diffuse gastric cancer families. Gastroenterology. 2001;121(6):1348-53.

15. Brooks-Wilson AR, Kaurah P, Suriano G, Leach S, Senz J, Grehan N, et al. Germline E-cadherin mutations in hereditary diffuse gastric cancer: assessment of 42 new families and review of genetic screening criteria. J Med Genet. 2004;41(7):508-17.

16. Cisco RM, Ford JM, Norton JA. Hereditary diffuse gastric cancer: implications of genetic testing for screening and prophylactic surgery. Cancer. 2008;113(7 Suppl):1850-6.

17. Lynch HT, Silva E, Wirtzfeld D, Hebbard P, Lynch J, Huntsman DG. Hereditary diffuse gastric cancer: prophylactic surgical oncology implications. Surg Clin N Am. 2008;88(4):759-78. vi-vii.

18. Fitzgerald RC, Caldas C. Familial gastric cancer-clinical management. Best Pract Res. 2006;20(4):735-43.

19. Chung DC, Yoon SS, Lauwers GY, Patel D. Case records of the Massachusetts General Hospital. Case 22-2007. A woman with a family history of gastric and breast cancer. N Engl J Med. 2007;357(3):283-91.

20. Concolino P, Papa V, Mozzetti S, Ferlini C, Pacelli F, Martinelli $\mathrm{E}$, et al. The unsolved enigma of $\mathrm{CDH} 1$ down-regulation in hereditary diffuse gastric cancer. J Surg Res. 2004;121(1):50-5.

21. Dussaulx-Garin L, Blayau M, Pagenault M, Le Berre-Heresbach $\mathrm{N}$, Raoul JL, Campion JP, et al. A new mutation of E-cadherin gene in familial gastric linitis plastica cancer with extra-digestive dissemination. Eur J Gastroenterol Hepatol. 2001;13(6):711-5.

22. Fenton G. Hereditary diffuse gastric cancer: case history. Cancer Forum. 2007;31(3):162-5.

23. Francis WP, Rodrigues DM, Perez NE, Lonardo F, Weaver D, Webber JD. Prophylactic laparoscopic-assisted total gastrectomy for hereditary diffuse gastric cancer. JSLS. 2007;11(1):142-7.

24. Gayther SA, Gorringe KL, Ramus SJ, Huntsman D, Roviello F, Grehan N, et al. Identification of germ-line E-cadherin mutations in gastric cancer families of European origin. Cancer Res. 1998;58(18):4086-9.

25. Humar B, Toro T, Graziano F, Muller H, Dobbie Z, Kwang-Yang $\mathrm{H}$, et al. Novel germline CDH1 mutations in hereditary diffuse gastric cancer families. Hum Mutat. 2002;19(5):518-25.

26. Huntsman DG, Carneiro F, Lewis FR, MacLeod PM, Hayashi A, Monaghan KG, et al. Early gastric cancer in young, asymptomatic carriers of germ-line E-cadherin mutations. N Engl J Med. 2001;344(25):1904-9. 
27. Iida S, Akiyama Y, Ichikawa W, Yamashita T, Nomizu T, Nihei $\mathrm{Z}$, et al. Infrequent germ-line mutation of the E-cadherin gene in Japanese familial gastric cancer kindreds. Clin Cancer Res. 1999;5(6):1445-7.

28. Ikonen T, Matikainen M, Mononen N, Hyytinen ER, Helin HJ, Tommola S, et al. Association of E-cadherin germ-line alterations with prostate cancer. Clin Cancer Res. 2001;7(11):3465-71.

29. Jonsson BA, Bergh A, Stattin P, Emmanuelsson M, Gronberg H. Germline mutations in E-cadherin do not explain association of hereditary prostate cancer, gastric cancer and breast cancer. Int J Cancer. 2002;98(6):838-43.

30. Keller G, Vogelsang H, Becker I, Hutter J, Ott K, Candidus S, et al. Diffuse type gastric and lobular breast carcinoma in a familial gastric cancer patient with an E-cadherin germline mutation. Am J Pathol. 1999;155(2):337-42.

31. Kim HC, Wheeler JM, Kim JC, Ilyas M, Beck NE, Kim BS, et al. The E-cadherin gene (CDH1) variants T340A and L599V in gastric and colorectal cancer patients in Korea. Gut. 2000;47(2):262-7.

32. Kusano M, Kakiuchi H, Mihara M, Itoh F, Adachi Y, Ohara M, et al. Absence of microsatellite instability and germline mutations of E-cadherin, APC and p53 genes in Japanese familial gastric cancer. Tumour Biol. 2001;22(4):262-8.

33. Lynch HT, Grady W, Lynch JF, Tsuchiya KD, Wiesner G, Markowitz SD. E-cadherin mutation-based genetic counseling and hereditary diffuse gastric carcinoma. Cancer Genet Cytogenet. $2000 ; 122(1): 1-6$.

34. Lynch HT, Kaurah P, Wirtzfeld D, Rubinstein WS, Weissman S, Lynch JF, et al. Hereditary diffuse gastric cancer: diagnosis, genetic counseling, and prophylactic total gastrectomy. Cancer. 2008;112(12):2655-63.

35. Moran CJ, Joyce M, McAnena OJ. CDH1 associated gastric cancer: a report of a family and review of the literature. Eur $\mathrm{J}$ Surg Oncol. 2005;31(3):259-64.

36. More H, Humar B, Weber W, Ward R, Christian A, Lintott C, et al. Identification of seven novel germline mutations in the human E-cadherin (CDH1) gene. Hum Mutat. 2007;28(2):203.

37. Newman EA, Mulholland MW. Prophylactic gastrectomy for hereditary diffuse gastric cancer syndrome. J Am Coll Surg. 2006;202(4):612-7.

38. Oliveira C, Bordin MC, Grehan N, Huntsman D, Suriano G, Machado JC, et al. Screening E-cadherin in gastric cancer families reveals germline mutations only in hereditary diffuse gastric cancer kindred. Hum Mutat. 2002;19(5):510-7.

39. Oliveira C, Ferreira P, Nabais S, Campos L, Ferreira A, Cirnes L, et al. E-Cadherin (CDH1) and p53 rather than SMAD4 and caspase-10 germline mutations contribute to genetic predisposition in Portuguese gastric cancer patients. Eur J Cancer. 2004;40(12):1897-903.

40. Oliveira C, Moreira H, Seruca R, de Oliveira MC, Carneiro F. Role of pathology in the identification of hereditary diffuse gastric cancer: report of a Portuguese family. Virchows Arch. 2005;446(2):181-4.

41. Oliveira C, de Bruin J, Nabais S, Ligtenberg M, Moutinho C, Nagengast FM, et al. Intragenic deletion of CDH1 as the inactivating mechanism of the wild-type allele in an HDGC tumour. Oncogene. 2004;23(12):2236-40.

42. Richards FM, McKee SA, Rajpar MH, Cole TR, Evans DG, Jankowski JA, et al. Germline E-cadherin gene (CDH1) mutations predispose to familial gastric cancer and colorectal cancer. Hum Mol Genet. 1999;8(4):607-10.

43. Rodriguez-Sanjuan JC, Fontalba A, Mayorga M, Bordin MC, Hyland SJ, Trugeda S, et al. A novel mutation in the E-cadherin gene in the first family with hereditary diffuse gastric cancer reported in Spain. Eur J Surg Oncol. 2006;32(10):1110-3.

44. Rogers WM, Dobo E, Norton JA, Van Dam J, Jeffrey RB, Huntsman DG, et al. Risk-reducing total gastrectomy for germline mutations in E-cadherin (CDH1): pathologic findings with clinical implications. Am J Surg Pathol. 2008;32(6):799-809.

45. Roviello F, Corso G, Pedrazzani C, Marrelli D, De Falco G, Berardi A, et al. Hereditary diffuse gastric cancer and E-cadherin: description of the first germline mutation in an Italian family. Eur J Surg Oncol. 2007;33(4):448-51.

46. Roviello F, Corso G, Pedrazzani C, Marrelli D, De Falco G, Suriano G, et al. High incidence of familial gastric cancer in Tuscany, a region in Italy. Oncology. 2007;72(3-4):243-7.

47. Salahshor S, Haixin L, Huo H, Kristensen VN, Loman N, Sjoberg-Margolin S, et al. Low frequency of E-cadherin alterations in familial breast cancer. Breast Cancer Res. 2001;3(3):199-207.

48. Schrader KA, Masciari S, Boyd N, Wiyrick S, Kaurah P, Senz J, et al. Hereditary diffuse gastric cancer: association with lobular breast cancer. Fam Cancer. 2008;7(1):73-82.

49. Shinmura K, Kohno T, Takahashi M, Sasaki A, Ochiai A, Guilford $\mathrm{P}$, et al. Familial gastric cancer: clinicopathological characteristics, RER phenotype and germline p53 and E-cadherin mutations. Carcinogenesis. 1999;20(6):1127-31.

50. Suriano G, Oliveira C, Ferreira P, Machado JC, Bordin MC, De Wever $\mathrm{O}$, et al. Identification of $\mathrm{CDH} 1$ germline missense mutations associated with functional inactivation of the E-cadherin protein in young gastric cancer probands. Hum Mol Genet. 2003;12(5):575-82.

51. Suriano G, Yew S, Ferreira P, Senz J, Kaurah P, Ford JM, et al. Characterization of a recurrent germ line mutation of the E-cadherin gene: implications for genetic testing and clinical management. Clin Cancer Res. 2005;11(15):5401-9.

52. Suriano G, Seixas S, Rocha J, Seruca R. A model to infer the pathogenic significance of $\mathrm{CDH} 1$ germline missense variants. J Mol Med (Berl). 2006;84(12):1023-31.

53. Tanis PJ, Ten Kate FJ, van Lanschot JJ. No mucosal escape of signet-ring cell carcinoma for ten years in a patient with familial aggregation of gastric cancer. J Surg Oncol. 2008;97(3):294-6.

54. Wang Y, Song JP, Ikeda M, Shinmura K, Yokota J, Sugimura H. Ile-Leu substitution (I415L) in germline E-cadherin gene (CDH1) in Japanese familial gastric cancer. Jpn $\mathrm{J}$ Clin Oncol. 2003;33(1):17-20.

55. Yabuta T, Shinmura K, Tani M, Yamaguchi S, Yoshimura K, Katai $\mathrm{H}$, et al. E-cadherin gene variants in gastric cancer families whose probands are diagnosed with diffuse gastric cancer. Int $\mathrm{J}$ Cancer. 2002;101(5):434-41.

56. Yoon KA, Ku JL, Yang HK, Kim WH, Park SY, Park JG. Germline mutations of E-cadherin gene in Korean familial gastric cancer patients. J Hum Genet. 1999;44(3):177-80.

57. Zhang Y, Liu X, Fan Y, Ding J, Xu A, Zhou X, et al. Germline mutations and polymorphic variants in MMR, E-cadherin and MYH genes associated with familial gastric cancer in Jiangsu of China. Int J Cancer. 2006;119(11):2592-6.

58. Zhu ZG, Yu YY, Zhang Y, Ji J, Zhang J, Liu BY, et al. Germline mutational analysis of $\mathrm{CDH} 1$ and pathologic features in familial cancer syndrome with diffuse gastric cancer/breast cancer proband in a Chinese family. Eur J Surg Oncol. 2004;30(5):531-5.

59. Barber ME, Save V, Carneiro F, Dwerryhouse S, Lao-Sirieix P, Hardwick RH, et al. Histopathological and molecular analysis of gastrectomy specimens from hereditary diffuse gastric cancer patients has implications for endoscopic surveillance of individuals at risk. J Pathol. 2008;216(3):286-94.

60. Carneiro F, Huntsman DG, Smyrk TC, Owen DA, Seruca R, Pharoah P, et al. Model of the early development of diffuse gastric cancer in E-cadherin mutation carriers and its implications for patient screening. J Pathol. 2004;203(2):681-7.

61. Caron O, Schielke A, Svrcek M, Flejou JF, Garzon J, Olschwang $\mathrm{S}$, et al. Usefulness of prophylactic gastrectomy in a novel large hereditary diffuse gastric cancer (HDGC) family. Am J Gastroenterol. 2008;103(8):2160-1. 
62. Charlton A, Blair V, Shaw D, Parry S, Guilford P, Martin IG. Hereditary diffuse gastric cancer: predominance of multiple foci of signet ring cell carcinoma in distal stomach and transitional zone. Gut. 2004;53(6):814-20.

63. Chun YS, Lindor NM, Smyrk TC, Petersen BT, Burgart LJ, Guilford PJ, et al. Germline E-cadherin gene mutations: is prophylactic total gastrectomy indicated? Cancer. 2001;92(1):181-7.

64. Framp A. Diffuse gastric cancer. Gastroenterol Nurs. 2006;29(3): 232-6. quiz 6-8.

65. Gaya DR, Stuart RC, McKee RF, Going JJ, Davidson R, Stanley AJ. E-cadherin mutation-associated diffuse gastric adenocarcinoma: penetrance and non-penetrance. Eur J Gastroenterol Hepatol. 2005; 17(12):1425-8.

66. Gaya DR, Stuart RC, Going JJ, Stanley AJ. Hereditary diffuse gastric cancer associated with E-cadherin mutation: penetrance after all. Eur J Gastroenterol Hepatol. 2008;20(12):1249-51.

67. Lewis FR, Mellinger JD, Hayashi A, Lorelli D, Monaghan KG, Carneiro F, et al. Prophylactic total gastrectomy for familial gastric cancer. Surgery. 2001;130(4):612-7. discussion 7-9.

68. Lynch HT, Grady W, Suriano G, Huntsman D. Gastric cancer: new genetic developments. J Surg Oncol. 2005;90(3):114-33; discussion 33.

69. Medina-Franco H, Barreto-Zuniga R, Garcia-Alvarez MN. Preemptive total gastrectomy for hereditary gastric cancer. J Gastrointest Surg. 2007;11(3):314-7.

70. Mukherjee A, McGarrity T, Staveley-O'Carroll K, Ruggiero F, Baker M. Hereditary diffuse gastric cancer: lifesaving potential of prophylactic gastrectomy. Community Oncol. 2009;6(1):41-5.
71. Norton JA, Ham CM, Van Dam J, Jeffrey RB, Longacre TA, Huntsman DG, et al. CDH1 truncating mutations in the E-cadherin gene: an indication for total gastrectomy to treat hereditary diffuse gastric cancer. Ann Surg. 2007;245(6):873-9.

72. Shaw D, Blair V, Framp A, Harawira P, McLeod M, Guilford P, et al. Chromoendoscopic surveillance in hereditary diffuse gastric cancer: an alternative to prophylactic gastrectomy? Gut. 2005; 54(4):461-8.

73. van Kouwen MC, Drenth JP, Oyen WJ, de Bruin JH, Ligtenberg MJ, Bonenkamp JJ, et al. [18F]Fluoro-2-deoxy-D-glucose positron emission tomography detects gastric carcinoma in an early stage in an asymptomatic E-cadherin mutation carrier. Clin Cancer Res. 2004;10(19):6456-9.

74. Oelschlager BK, Yigit T, Kaufman JA, Pellegrini CA. Hereditary diffuse gastric cancer. Med Gen Med. 2005;7(3):16.

75. Grady WM, Willis J, Guilford PJ, et al. Methylation of the $\mathrm{CDHI}$ promoter as the second genetic hit in hereditary diffuse gastric cancer. Nat Genet. 2000;26:16-7.

76. Machado JC, Oliveira C, Carvalho R, et al. E-cadherin gene $(\mathrm{CDH1})$ promoter methylation as the 2 nd hit in sporadic diffuse gastric carcinoma. Oncogene. 2001;20:1525-8.

77. Kaurah P, Fitzgerald R, Dwerryhouse S, Huntsman DG. Pregnancy after prophylactic total gastrectomy. Fam Cancer. 2010; 9(3):331-4. 